\title{
Identity Statuses Scale in EFL Settings: A Case of Formal and Informal Contexts
}

\section{Leila Sayah}

\author{
Phd Candidate at Ferdowsi University of Mashhad, Mashhad Iran,
} International Branch

Email: Sayah2015@gmail.com

\author{
Reza Pishghadam \\ Associate Professor, Ferdowsi University of Mashhad, \\ Postal Address: English Language Department, Ferdowsi University of Mashhad, Mashhad- Iran \\ Email: Pisghadam@um.ac.ir
}

\section{Behzad Ghonsooly}

Associate Professor, Ferdowsi University of Mashhad, Mashhad- Iran Email: Ghonsooly@ferdowsi.um.ac.ir

\section{Azar Hosseini Fatemi}

Associate Professor, Ferdowsi University of Mashhad, Mashhad- Iran Email: hfatemi@ferdowsi.um.ac.ir

Doi:10.5901/mjss.2014.v5n27p1530

\begin{abstract}
The considerable literature on identity formation as the critical basis of individuals' wellbeing made the researchers design a delicate Identity Statuses Scale (ISS) inspired by Marcia's (1966) identity statuses. The observed variables were proportionate with the current elements of religion, politics, society, and ideology. The scale was administered to 520 male and female students in two settings of public schools and English institutes. The main objectives of this study was first to validate the identity scale via Structural Equation Modeling (SEM) and second to realize the age, gender, and school differences of the participants of the study. Principle Component Analysis extracted four underlying factors in the study. The result revealed the direct correlation of social interpersonal identity with other three factors as the dominant statuses. It was further explored that it is the momentum circumstances and intense stance of certain sub factors that determine the type and intensiveness of identity statuses representation.
\end{abstract}

Keywords: statuses, variables, validate, correlation, social interpersonal

\section{Introduction}

Identity "a self-structure - an internal, self- constructed, dynamic organization of drives, abilities, beliefs, and individual history" (Marcia, 1980, p. 109) has gained an influential attention in hundreds of cross sectional research studies each focusing on different manifestation of identity construction and emphasizing social, cultural, religious, political, and psychological distinctiveness. The focus on self exploration and self commitment of young and late adolescents' identity formation incorporating by social, parental, educational, cultural, and psychological changes extended after Erikson's stages $(1950,1968)$ and Marcia's statuses $(1966,1980)$ of identity construction and development. They theorized and applied ego identity stages and statuses among young and late adolescents _a critical period in which senses of growth, individuation, connectedness, and affirmed commitment and exploration take place.

Waterman (1982) acknowledged that the nature of the social expectations related to identity choices arising within the family, the schools, and the peer group will contribute to the particular identity development pathways employed but among substantial studies deployed on timing, direction, development, antecedent conditions, age, and gender differences on identity formation, (Bang, 2002; Bradley \& Matsukis, 2000; Knafo et al 2004; Kumru \& Thompson, 2003; 
Lee et al, 1998; Smits et al, 2008), very few studies investigated the site influencing identity formation of the participants (Pishghadam \& Motakef, 2011; Pishghadam \& Navari, 2009;). They had little contribution to the sharp relationship between religion, life style, political, social and interpersonal identities. The specific similarities and contrasts between the identity statuses as were specified by Marcia (1966) and different identities were ignored.

Since EFL classrooms are the overlapping context with clashing expectations over social, cultural, religious, and political perspectives where individuals may accommodate to the new cultural identities ending with a possible perpetual identity change (Hong et al., 2007), and while the formal and informal contexts provide individuals with identity exploration as well as developing shifts between statuses, and the wider socio-cultural values (Waterman, 1982), it was determined to design an identity scale appropriate for different so- called perspectives, and to discover the students' identity statuses regarding their home culture heritage in two settings of public school and private English institutes. The age and gender were assigned as the fixed variables of this study for the following rationales. First rationale was that almost all young adolescents encounter ambiguity of status between the ages of 15 and 17 (Coleman, 1992). The second rationale was the fact that in some studies, males and females were distinguished with certain fixed identity statuses (Yunus \& Kamal, 2010; Sandhu \& Tung, 2006). On account of these rationales, it was intended to explore the identity formation of male and female students of public school and private English institutes with the age range of 15- 18 (the exact age range of Iranian public school students).

\section{Theoretical Framework}

"Ego identity arose from the extension of psychoanalytic theory known as "ego psychology" (Marcia \& Kroger, 2011, p. 31) but the original concept of ego functions was first put forward by Freud (1946) in his three phases of ego identity development as: 1. Structure experiencing in external reality to prevent painful affects; 2. Ego relating to intrapsychic dangers by id fantasies; and 3. Ego freed from externality enjoying its unique genetic roots. Edwards (2009) notes that "besides our personal sense of self, we also have social identities based upon the various groups to which we belong. Thus, we can maintain and enhance self-esteem through valued social affiliations, as well as by purely personal activities and achievements" (p.27). Goffman (1959) views identity as the socially constructed consequence of our interconnections with others by applying variety of roles in various situations.

Erikson (1963) was the first to propose eight developmental tasks that four of them occur in childhood: trust versus mistrust in infancy, autonomy versus shame/doubt in toddlerhood, initiative versus guilt during preschool, and industry versus inferiority during school-age. He emphasized adolescence's self-exploration, negotiation of external factors and reconciliation of identity that would develop during late adulthood. He also distinguished this process as 'identity crisis' that would lead to identity confusion if not be explored and be resolved. Autonomy vs shame and doubt is characterized by a "sudden violent wish to have a choice" and becomes "decisive for the ratio of love and hate, cooperation and willfulness, freedom of self-expression and its suppression" (Erickson, 1963, p. 252).

Marcia $(1966,1980)$ based on Erickson's adherence to roles followed by search, framed four stages of identity statuses in terms of time of reassessment of commitment as identity diffusion, foreclosure, moratorium, and identity achievement. The term crisis was selected to represent the "adolescent's period of engagement in choosing among meaningful alternatives" (Marcia, p. 551) and the term commitment was selected to refer to the degree of personal investment exhibited by the individual. He described "identity achievement" and "identity diffusion" as "polar alternatives of status inherent in Erikson's theory" (p. 551).

According to Marcia (1966), an identity-achievement "has experienced a crisis period and is committed to an occupation and ideology" (p. 552). He identified two intermediate points of concentration, the

\section{Moratorium and Foreclosure Statuses}

The identity Moratorium is characterized by a period of crisis without clear commitments; however, the moratorium is actively engaged in attempts to resolve the crisis and make commitments. Identity-foreclosure is commitment without experiencing crisis. Personal beliefs are internalized and individuals may display authoritarianism, prevent making their decisions and prefer to be told what to do. (Marcia, 1966) notes that the identity diffusion status is associated with lower levels of moral reasoning, difficulty thinking under stress, susceptibility to manipulation of self- esteem, and conformity to external demands.

Marcia (1966) found "no confirmation of relating ego identity to resistance to change in self-esteem" (p. 557). He also found that identity achievement group scored highest on stressful concept tasks but less on authoritarian values and self-esteem. Foreclosures adopted authoritarian values such as obedience, strong leadership, and respect for authority 
but more poor application of stressful concept tasks was observed. Beginning in the 1970s Waterman and Geary and Waterman (1974) in longitudinal investigations found the identity achievement and moratorium statuses to increase and the foreclosure and diffusion statuses to decrease in frequency over time across both vocational and ideological domains. Waterman (1999) summarizes identity statuses in nomological net in the following important patterns:

(1) Identity achievers typically score higher than others on measures of (a) Loevinger's ego stages, (b) principled moral reasoning, (c) cultural sophistication, and (d) intimacy, and score lower than those in other statuses on (e) psychiatric problems. (2) Moratoriums typically score higher than other statuses on measures of (a) anxiety and (b) conflict with parents and score lower than those in other statuses on (c) authoritarianism and (d) psychological well-being. (3) Foreclosures score higher on (a) authoritarianism, (b) familial attachment, (c) conventional moral reasoning, and (d) conformity and score lower on (e) anxiety. (4) Individuals in the identity diffusion status score higher on measures of (a) pre conventional moral reasoning and (b) the isolate intimacy status and lower on measures of (c) Loevinger's ego stages and (d) measures of early psychosocial development.

According to Bradley and Matsukis (2000), young diffused and moratorium people have a high propensity towards reckless pursuits. They included a reckless behavior scale activities like involvement in drug use and drink driving closest among university students. Majority of diffused and moratorium respondents affirmed some involvement in marijuana smoking. Achieved and foreclosed participants addressed religion as a reason for abstaining from such behaviors.

Schwartz and Cote and Arnett (2005) realized that commitment differed between the default and developmental individualization clusters and the diffuse/avoidant identity was higher in default individualization, and indices of diffusion and moratorium were highest in default individualization. They also found that in both the ideological and interpersonal domain clusters, diffusion, foreclosure, and moratorium scores were higher in the default individualization whereas achievement in the developmental cluster. Crocettia and Rubinib and Meeus (2008) designed an identity model comprised of three dimensions: commitment, in-depth exploration and reconsideration of commitment among 1952 adolescents. They found that commitment was related to in-depth exploration, and the latter was positively related to reconsideration of commitment that was positively related to self-concept clarity, extroversion and emotional stability.

Berzonsky and Cieciuch and Duriez and Soenens (2011), designed identity styles scale and found that an informational style relates to independence and autonomy. Individuals with a diffuse-avoidant style engage in behaviors as conduct disorders, delinquency, illegal drug use, and alcohol abuse. An informed, rational approach to identity issues was related to being independent and self-governing that exceeded personal pleasure and self-indulgence. Meeus and ledema and Helsen and Vollebergh (2011) suggested new status of searching moratorium in their scale while asserting that this status showed lower levels of depressive symptoms than moratoriums in the early-to-middle adolescent and achievers and early closures showed the highest levels of adjustment while moratoriums lacked strong commitments and had a high level of depressive symptoms.

It is important to notify that Bennion and Adams' (1986), and recent Meeus et al.'s (2011) and Berzonsky et al.'s (2011) identity questionnaires were numerously used by different researchers but there were two different reasons that made us design the new identity scale. The first and the main reason was that we observed significant socio - cultural and religious differences between these questionnaires' items and Iranian culture. Secondly, these questionnaires were designed to identify specific measures as in-depth exploration, reconsideration of commitment, and informational inventory scale which were not the main objectives of this study. Taking these into account, this study determines to identify two goals. First goal was to validate the new designed identity status scale suggested by the researchers among male and female students of public school and English Institutes via Structural Equation Modeling (SEM). The second goal was to explore age, gender, and the settings' differences considering Marcia's four identity statuses- foreclosure, diffusion, moratorium, and identity achievement.

\section{Methodology}

\subsection{Research Method}

To investigate young adolescents' identity statues, adolescents' commitment to home culture, the site influencing adolescents enrichment or derichment in EFL classrooms, this study attempted to provide some quantitative and qualitative methods.

\subsection{Participants}

This study was performed on 296 male and female students of public schools (144 males, 152 females) and 224 private 
language institutes' students (102 males, 122 females) with the age range of 15-18 in Ahvaz. The rationale of selecting this age range was the adolescents' uncertainties and vagueness about their status between the age ranges of 15-17 (Arnnet, 1992). Since the age range of Iranian public school students are 15-18, the age range 18 was added to the study. Public schools contain homogeneous students with the fixed age range of 15 to 18 , and heterogeneous students with variety of age ranges could be observed in the private English institutes due to the policy of admitting the students on the basis of their adequate English level proficiency. On account of this limitation, different methods of sampling were administrated: The public school students were randomly chosen by selecting odd or even numbers of the students written in the classroom formal notebooks. The English institutes students, on the other hand, were chosen nonrandomly by administrating the questionnaire among large number of language learners to acquire the exact age range of 15- 18. The foretold reason and excluding the unanswered questionnaire came out with 520 questionnaires out of 1000 participants in more than two semesters.

\subsection{Instrumentation}

Inspired by Adams (1998); Bennion and Adams (1986), and Berzonsky et al.'s (2011) questionnaires on identity statuses, the new scale of identity was designed by authors to measure the students' identity statuses in two settings of public schools and private English institutes. The scale comprises 25 items and is a multiple choice scale . Focusing on Marcia's (1966) identity statuses, the scoring was specified as (1) Diffusion; (2) Foreclosure; (3) Moratorium, and (4) Identity achievement. To explore the reliability of the scale, Cronbach's Alpha was deployed and the reliability was calculated as .83. Conducting SEM via LISREL program ended with significant fit indices affirming the construct validity of the scale.

\subsection{Procedure}

In this study, two stages were conducted respectively. First stage was to design ISS and then apply it in two settings of public school and private English institutes. The second stage of the study comprised validating the scale and analyzing the data that itself incorporated three major phases:

In designing the items of the scale, the most practiced issues in Iranian social interpersonal, cultural, religious, and political topics were taken into consideration. The couple of experts examined the wording of the scale to maintain the clarity. Each item implied one of the four identity statuses- diffusion, foreclosure, moratorium, and identity achievement. The data collection initiated in December 2013 first in public schools and with a month interval in English institutes. 15 to 20 minutes was scheduled to answer the scale. Since the questionnaire is a multiple choice scale and each item presents one of the four identity statuses, the students were instructed to choose the choice that best demonstrates their identity. Confidentiality of the results of the scale was assured by the researchers.

Analyzing the results of the scale as the second stage of the study, comprised three phases respectively. In the first phase, the overall reliability of the scale questions as well as the internal reliability of the latent variables were identified through Cronbach alpha. The Kaiser-Meyer-Olkin Measure of Sampling Adequacy (KMO) and Barlett's Test of Sphericity were used to distinguish the suitability of the scale items. Correlation matrix for coefficients and Monte Carlo Principal Component Analysis (PCA) were employed to specify parallel analysis of the scale's items. Varimax with Kaiser PCA orthogonal rotation for normalization and the Scree test diagram were used to distinguish the exact number of latent variables and their statements. In the second phase of this study, a process of SEM was used via LISREL program version 8 to recognize the construct validity of the identity status scale. In the third phase of the analysis, the multivariate normality, Mahalanobis distances and multivariate outliners were calculated. Then Chi-square test was run to identify the significant differences between the scale's underlying factors. Moreover, MANOVA was run to observe the relationship between the independent variables (age, gender, and school) and the underlying factors.

\section{Results}

\subsection{Reliability of the Questionnaire}

To assess the reliability of the identity status questionnaire, Cronbach's Alpha was deployed and the reliability of the 25 items was estimated as .839. None of the items were excluded since the reliability of each factor (see Table 1) ranged from .76 to .82 . 
Table 1. Reliability of Each Factor

\begin{tabular}{ccc}
\hline Factors & Cronbach's Alpha & $\mathrm{N}$ \\
\hline Factor 1 & .827 & 5 \\
Factor 2 & .767 & 10 \\
Factor 3 & .778 & 5 \\
Factor 4 & .810 & 5 \\
\hline
\end{tabular}

\subsection{Construct validity}

To assess the suitability of the questionnaire's factors, the Kaiser-Meyer-Olkin Measure of Sampling Adequacy (KMO) and Barlett's Test of Sphericity was calculated along with the correlation matrix for coefficients of .3. As it is observed in Table 2, the result of (KMO) value is above .6 and it is .82 and the Barlett's Test of Sphericity value is significant $(p=.00)$ and it strongly contributes to the suitability of the factor model.

Table 2. KMO and Bartlett's Test

\begin{tabular}{|ccc|}
\hline \multicolumn{2}{|c|}{ Kaiser-Meyer-Olkin Measure of Sampling Adequacy. } & .813 \\
& Approx. Chi-Square & 2940.992 \\
Bartlett's Test of Sphericity & df & 300 \\
& Sig. & .000 \\
\hline
\end{tabular}

Principal Component Analysis (PCA) extracted 6 factors with eigenvalues greater than 1.0. The results achieved through Scree test diagram (see Figure 1) provided an appropriate four factor solution of the groupings in questionnaires items.

Figure 1. Scree Test for distinguishing the number of factors

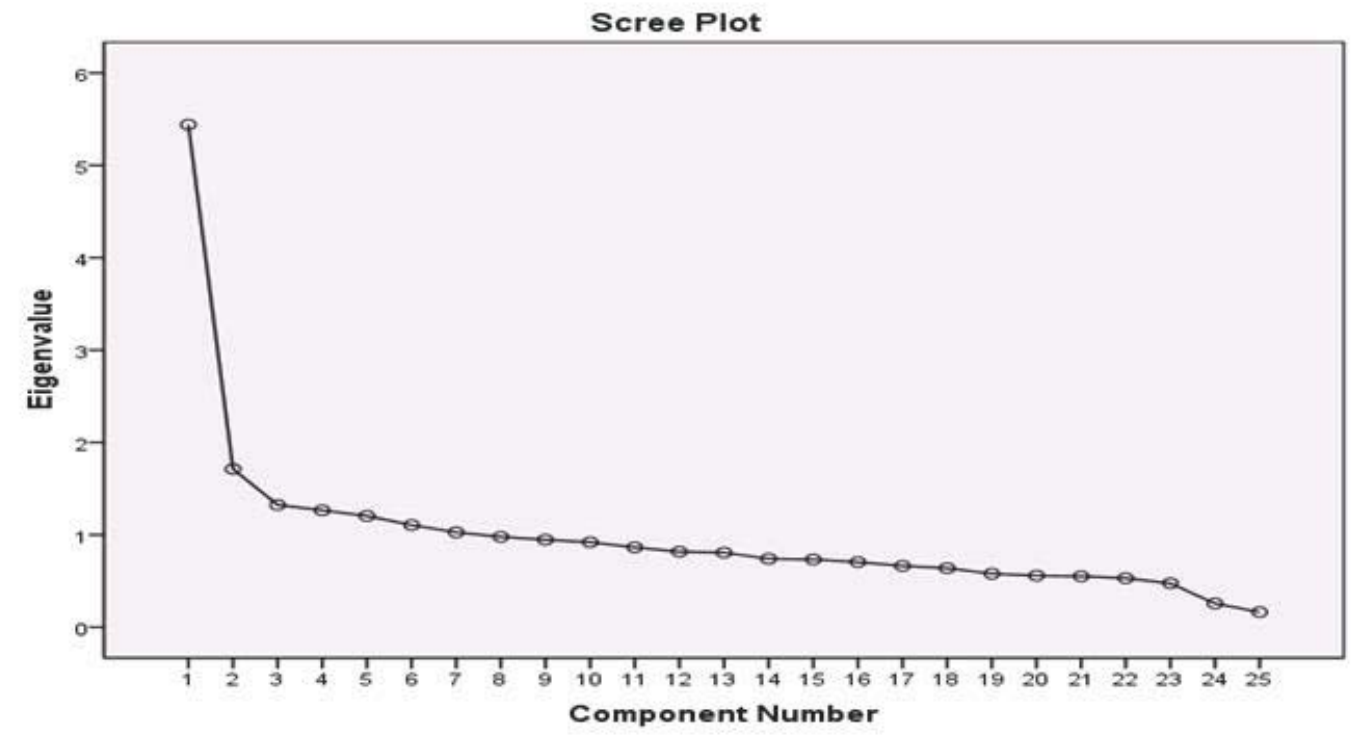

To obtain the exact number of factors and their statements, Varimax with Kaiser

PCA orthogonal rotation for normalization, shown in Table 3 was run. Since all Random Eigenvalues were larger than the criterion value in parallel analysis (see Table 4), and the result of Varimax for normalization is mostly .4 to .7, we could retain all the four factors consisting of $5,10,5,5$ items respectively. 
Table 3. Rotated Components Obtained via Principal Component Analysis and their Loadings

\begin{tabular}{|c|c|c|c|}
\hline Component 1 & Component 2 & Component 3 & Component 4 \\
\hline Religion= .744 & Future $=.641$ & Clothes $=.545$ & Political Prejudice $=.723$ \\
\hline Religious Countries/ cities= . & 5 Man/Woman Role= .39 & Film $=.450$ & Political Independence $=.550$ \\
\hline Religious Ceremonies $=.481$ & Cell phone $=.469$ & First Language $=.56$ & Political International Communication $=.594$ \\
\hline Religions $=.376$ & Life Style $=.409$ & Music $=.749$ & Political Party Dependency $=.769$ \\
\hline \multirow[t]{6}{*}{ Church/Mosque $=.514$} & $\mathrm{Job}=.407$ & Ancient Sites $=.452$ & Political Issues $=.756$ \\
\hline & Social Laws $=.448$ & & \\
\hline & Friend $=.425$ & & \\
\hline & Internet $=.488$ & & \\
\hline & Marriage $=.445$ & & \\
\hline & Decision Making $=.415$ & & \\
\hline
\end{tabular}

Rotation Method: Varimax with Kaiser Normalization

The four factors were distinguished as 'religious identity', 'social interpersonal identity', 'cultural identity' and 'political identity'. You can see the identity status scale's all four factors and their items in Table 5.

Table 4. Factors of the Scale

\begin{tabular}{lccc}
\hline Areas & Statements & N of items & Percentage \\
\hline Religious Identity & $1,8,12,21,25$ & 5 & 20 \\
Social Interpersonal Identity & $2,6,7,9,10,11,16,18,19,22$ & 10 & 40 \\
Cultural Identity & $3,5,14,15,23$ & 5 & 20 \\
Political Identity & $4,13,17,20,23$ & 5 & 20 \\
& Total & 15 & 100 \\
\hline
\end{tabular}

\subsection{SEM}

To analyze the internal interaction between the scale's four factors, the model demonstrated in Figure 2 was represented. When converging the four factors in LISREL program, semi identical relationship was revealed between social interpersonal and religious factor and social interpersonal and political factor. Cultural and political factors displayed a negative correlation (see Figure 2).

Figure 2. Model of Interaction between Underlying Factors

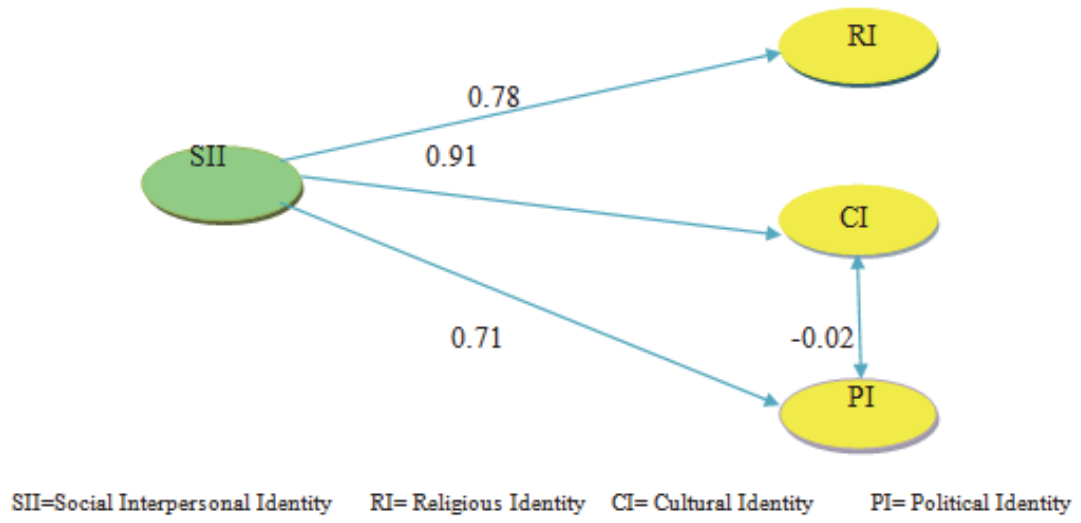

The questionnaires' factors were analyzed through LISREL program and different model fit indices were calculated. The most common calculated fit indices were goodness of fit (GFI), Normed fit index (NFI), Incremental fit index (IFI), Comparative fit index, Tucker Lewis index (TLI) and the root mean square error of approximation (RMESA). Since the result of all indices were significant with Chi-square divided by degree of freedom less than 3, RMSEA that less than .05, $\mathrm{CFI}, \mathrm{GFI}$, and NFI which were more than .90, the factor analysis was strongly appropriate and validated (see Table 6).

Table 5. Goodness of Fit Indices

\begin{tabular}{|c|c|c|c|c|c|c|c|}
\hline Fit indices & X2/DF & GFI & NFI & IFI & TLI & CFI & RMSEA \\
\hline Model & 2.3 & 0.94 & 0.92 & 0.93 & 0.99 & 0.93 & 0.04 \\
\hline
\end{tabular}




\subsection{Questionnaire Results}

First to test multivariate normality, Mahalanobis distances and multivariate outliners were calculated. Since the Mahalanobis distance was 19.9 and all extreme values in multivariate outliners were extremely smaller than this distance, all cases retained in the data file. Then Chi-square test was run to explore the significant differences between the study's four latent variables- religious, social interpersonal, cultural, and political factors. Finally, MANOVA was run to observe the relationship between our independent variables (age, gender, and school) and different identity statuses factors religious status, social interpersonal status, cultural status, and political status- among the male and female students of the two settings. The Chi-square result of the four identity statuses revealed a harsh decline of religious identity status in comparison with other three factors (see Table 6). Regarding mean scores in two settings of public schools and English institutions, male and female students scored higher in perceiving the four statues in English institutes in comparison with public schools. Moreover, females reported higher levels of social interpersonal and cultural identity statuses than males in both settings (see Table 9)

Table 6: Chi-square Result of Identity ISS Factors

\begin{tabular}{|c|c|c|c|c|}
\hline \multicolumn{5}{|c|}{ Test Statistics } \\
\hline & Religious IS & Social interpersonal IS & Cultural IS & Political IS \\
\hline Chi-Square & $140.831^{\mathrm{a}}$ & $290.831^{\mathrm{b}}$ & $267.462^{\mathrm{c}}$ & $190.215^{\mathrm{a}}$ \\
$\mathrm{df}$ & 15 & 26 & 14 & 15 \\
Asymp. Sig. & .000 & .000 & .000 & .000 \\
\hline
\end{tabular}

As it is seen in Table 8, participants appeared to be moratorium and identity achievers at social interpersonal status. Regarding political and religious identity, participants appeared to be foreclosures, diffusions and moratoriums. Females estimated higher than males in manifesting identity achievement and moratorium status in social interpersonal status.

Table 8: The Frequency Result of Social Interpersonal Identity

\begin{tabular}{|c|c|c|c|c|c|c|c|}
\hline \multicolumn{2}{|l|}{ Male/Female } & \multicolumn{2}{|l|}{ School } & Frequency & Percent & Valid Percent & Cumulative Percent \\
\hline \multirow{20}{*}{ dimension0 } & \multirow{10}{*}{ Male } & \multirow{5}{*}{ Public School } & Foreclosure & 10 & 6.9 & 6.9 & 6.9 \\
\hline & & & Diffusion & 27 & 18.8 & 18.8 & 25.7 \\
\hline & & & Valid Moratorium & 38 & 26.4 & 26.4 & 52.1 \\
\hline & & & Identity Achievement & 69 & 47.9 & 47.9 & 100.0 \\
\hline & & & Total & 144 & 100.0 & 100.0 & \\
\hline & & \multirow{3}{*}{\multicolumn{2}{|c|}{$\begin{aligned} & \text { Foreclosure } \\
& \text { Diffusion }\end{aligned}$}} & 5 & 4.9 & 4.9 & 4.9 \\
\hline & & & & 10 & 9.8 & 9.8 & 14.7 \\
\hline & & & & 30 & 29.4 & 29.4 & 44.1 \\
\hline & & & Identity Achievement & 57 & 55.9 & 55.9 & 100.0 \\
\hline & & & Total & 102 & 100.0 & 100.0 & \\
\hline & \multirow{10}{*}{ Female } & \multirow{5}{*}{ Public school } & Foreclosure & 13 & 8.6 & 8.6 & 8.6 \\
\hline & & & Diffusion & 5 & 3.3 & 3.3 & 11.8 \\
\hline & & & Valid Moratorium & 52 & 34.2 & 34.2 & 46.1 \\
\hline & & & Identity Achievement & 82 & 53.9 & 53.9 & 100.0 \\
\hline & & & Total & 152 & 100.0 & 100.0 & \\
\hline & & \multirow{5}{*}{\multicolumn{2}{|c|}{$\begin{array}{l}\text { Foreclosure } \\
\text { Diffusion } \\
\text { English Institutions Valid } \\
\qquad \begin{array}{l}\text { Moratorium } \\
\text { Identity Achievement } \\
\text { Total }\end{array}\end{array}$}} & 3 & 2.5 & 2.5 & 2.5 \\
\hline & & & & 4 & 3.3 & 3.3 & 5.7 \\
\hline & & & & 44 & 36.1 & 36.1 & 41.8 \\
\hline & & & & 71 & 58.2 & 58.2 & 100.0 \\
\hline & & & & 122 & 100.0 & 100.0 & \\
\hline
\end{tabular}


Social interpersonal exhibited higher relationship with our independent variables in test of between subject affects: $F=$ 3.387, $p=.018$ and Partial Eta Squared $=.020$. Cultural identity status revealed the second higher correlation with the independent variables: $F=1.274, p=.283$ and Partial Eta Squared $=.008$ (see Table 9)

Table 9. Test of Between- Subjects Effects

\begin{tabular}{|c|c|c|c|c|c|c|c|}
\hline Source & Dependent Variable & Type III Sum of Squares & $d f$ & Mean Square & $\mathrm{F}$ & Sig. & Partial Eta Squared \\
\hline \multirow{4}{*}{ Gender * School } & \multirow{4}{*}{ dimension1 } & 36.588 & 1 & 36.588 & 3.650 & .057 & .007 \\
\hline & & .012 & 11 & .012 & .001 & .980 & .000 \\
\hline & & 54.949 & 1 & 54.949 & 8.410 & .004 & .017 \\
\hline & & 27.523 & 1 & 27.523 & 3.498 & .062 & .007 \\
\hline \multirow{4}{*}{ Gender * Age } & \multirow{4}{*}{ dimension1 } & 122.375 & 7 & 17.482 & 1.744 & .097 & .024 \\
\hline & & 148.599 & 7 & 21.228 & 1.091 & .368 & .015 \\
\hline & & 42.211 & 7 & 6.030 & .923 & .488 & .013 \\
\hline & & 202.904 & 7 & 28.986 & 3.684 & .001 & .049 \\
\hline \multirow{4}{*}{ School * Age } & \multirow{4}{*}{ dimension1 } & 40.743 & 3 & 13.581 & 1.355 & .256 & .008 \\
\hline & & 95.347 & 3 & 31.782 & 1.633 & .181 & .010 \\
\hline & & 6.332 & 3 & 2.111 & .323 & .809 & .002 \\
\hline & & 14.264 & 3 & 4.755 & .604 & .612 & .004 \\
\hline \multirow{4}{*}{ Gender * School * Age } & \multirow{4}{*}{$\begin{aligned} & \text { RISS } \\
& \text { dimension1 } \text { SInterISS } \\
& \text { CISS } \\
& \text { PISS } \\
&\end{aligned}$} & 18.937 & 3 & 6.012 & .630 & .596 & .004 \\
\hline & & 197.798 & 3 & 65.933 & 3.387 & .018 & .020 \\
\hline & & 24.976 & 3 & 8.325 & 1.274 & .283 & .008 \\
\hline & & 19.202 & 3 & 6.401 & .814 & .487 & .005 \\
\hline
\end{tabular}

There was a statistically significant difference between independent variables age, gender, and school on the combined dependent variables in multivariate tests: Wilks' Lambda=.963; $F=4.689, p=.001$; and Partial Eta squared=.037 (see Table 10).

Table 10. Multivariate Tests (Wilk's Lambada)

\begin{tabular}{|cl|c|c|c|c|c|c|}
\hline \multicolumn{2}{|c|}{ Effect } & Value & $\mathrm{F}$ & Hypothesis df & Error df & Sig. & Partial Eta Squared \\
\hline \multirow{5}{*}{ Intercept } & Pillai's Trace & .983 & $7232.280^{\mathrm{a}}$ & 4.000 & 493.000 & .000 & .983 \\
& Wilks' Lambda & .017 & $7232.280^{\mathrm{a}}$ & 4.000 & 493.000 & .000 & .983 \\
& Hotelling's Trace & 58.680 & $7232.280^{\mathrm{a}}$ & 4.000 & 493.000 & .000 & .983 \\
& Roy's Largest Root & 58.680 & $7232.280^{\mathrm{a}}$ & 4.000 & 493.000 & .000 & .983 \\
\hline \multirow{5}{*}{ Gender * School age } & .037 & $4.689^{\mathrm{a}}$ & 4.000 & 493.000 & .001 & .037 \\
& Pillai's Trace & .963 & $4.689 \mathrm{a}$ & 4.000 & 493.000 & .001 & .037 \\
& Wilks' Lambda & .038 & $4.689 \mathrm{a}$ & 4.000 & 493.000 & .001 & .037 \\
& Hotelling's Trace & .038 & .037 \\
& Roy's Largest Root & .038 & $4.689 \mathrm{a}$ & 4.000 & 493.000 & .001 & .037 \\
\hline
\end{tabular}

Since the frequency tables considering age and gender differences in public schools and English institutes were too long to display and also some items were almost identical in representing certain identity statuses, it was determined to display the most significant frequencies of some items in Tables 11 to 15. The frequency result of life style value in social interpersonal identity revealed no significant differences between the settings of the study_ public schools and English institutes_whereas considerable gender and age differences were observed considering this value. Males at the age range of 15 and 16 , displayed diffusion status in both settings whereas females at the same age range were both moratorium and identity achievers(see Table 11). As it is seen in Table 11, females represented more of moratorium and identity achievement statuses at the age range 17 and 18, while males' almost even frequency of diffusion and identity achievement statuses appeared more critical in both settings. 
Table 11: The frequency Result of Gender and Age differences Considering Life Style in SIIS

\begin{tabular}{|c|c|c|c|c|c|c|c|c|c|c|c|}
\hline \multirow{6}{*}{ Public School } & & & ency & ale/ & & \multirow{6}{*}{$\begin{array}{l}\text { English } \\
\text { Institutes }\end{array}$} & \multirow{2}{*}{ Age } & \multicolumn{4}{|c|}{ Frequency- Male/ Female } \\
\hline & Age & D & $\mathrm{F}$ & $M$ & IA & & & D & $\mathrm{F}$ & $M$ & IA \\
\hline & 15 & & & & 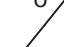 & & 15 & & & & \\
\hline & 16 & $1 / 4$ & & $9 / 6$ & 11 & & 16 & & & & \\
\hline & 17 & 14 & & $\frac{9}{15}$ & 22 & & 17 & & 8 & 17 & \\
\hline & 18 & & & 12 & 7 & & 18 & & & 15 & 17 \\
\hline
\end{tabular}

SIIS = Socialinterpersonal Identity Status D= Diffusion F= Foreclosure M=Moratorium IA= Identity Achievement

The frequency result of gender differences considering religious ceremonies and other religions (in religious identity) revealed significant age differences in both settings (see Table 12). While females' identity statuses fluctuated between diffusion and foreclosure statuses at the age range 15 to 16, males' diffusion identity status was more significant at the given age range in both setting. At the age 18 , a significant increase in frequency result of identity achievement status was formed in both males and females of public schools. Diffusion appeared to be the second high frequency for males and moratorium for females. But age did not result in any change in English institutions. Females still represented diffusion and foreclosure at the age 17 and 18 and males displayed diffusion and moratorium at the same age range.

Table 12: The frequency Result of Gender and Age differences Considering Religious Ceremonies in RIS

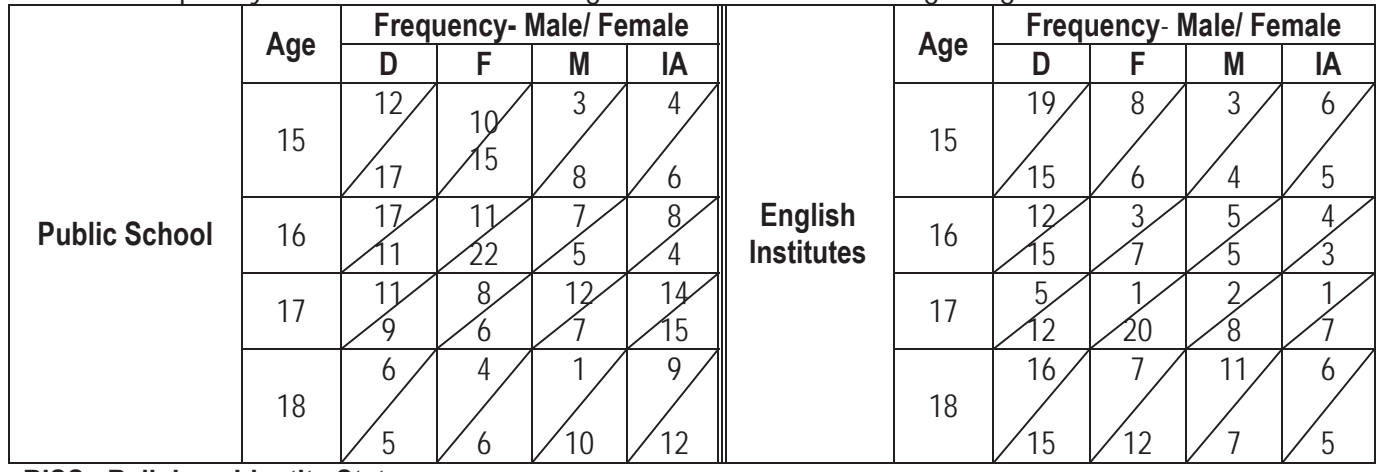

RISS= Religious Identity Status

Regarding cultural identity, significant differences were observed in first language, films, and music items in both settings (The close frequency result of these items made us to represent the frequency result of one item in Table 13). At the age range 15 to 18, both males appeared to be more moratorium and identity achievers in English institutes. Public school male students appeared to be more diffusion and females more of foreclosure and moratoriums.

Table 13: The frequency Result of Gender and Age differences Considering First Language in $\mathrm{CIS}$

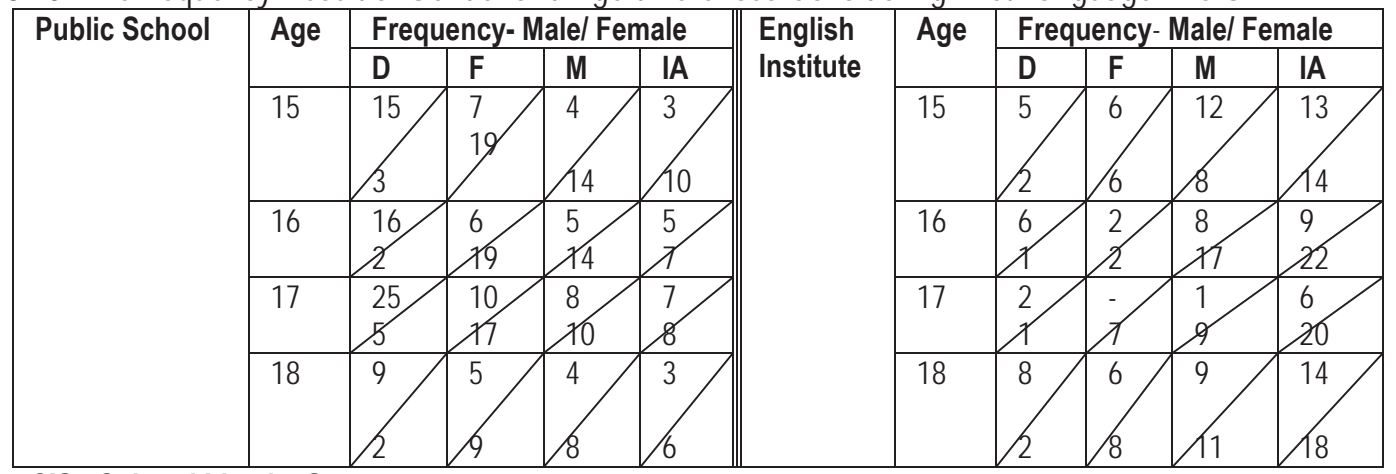

CIS= Cultural Identity Status 
As it is seen in Table 14, the considerable differences between both settings could be observed in international communication value (this item was almost identical with and political issues). Both males and females displayed more diffusion status at the age range 15 to 16 and the frequency result of identity achievement and diffusion statuses remained close at 17 to 18 for males in public schools. Males at English institutes represented more moratorium and identity achievement status at the age range 15 to 18. Females on the other hand, displayed more foreclosure and moratorium status in public school and moratorium and identity achievement in English institutes.

Table 14: The frequency Result of Gender and Age differences Considering Political International Communication in PIS

\begin{tabular}{|c|c|c|c|c|c|c|c|c|c|c|c|}
\hline \multirow{6}{*}{ Public School } & \multirow{2}{*}{ Age } & \multicolumn{4}{|c|}{ Frequency- Male/ Female } & \multirow{6}{*}{$\begin{array}{l}\text { English } \\
\text { Institutes }\end{array}$} & \multirow{2}{*}{ Age } & \multicolumn{4}{|c|}{ Frequency- Male/ Female } \\
\hline & & D & $\mathbf{F}$ & M & IA & & & D & $\mathbf{F}$ & M & IA \\
\hline & 15 & & & & & & 15 & & & & \\
\hline & 16 & & & & & & 16 & & & & \\
\hline & 17 & & 10 & 13 & $1 / 4$ & & 17 & & & & \\
\hline & 18 & & & & & & 18 & & & & \\
\hline
\end{tabular}

PIS= Political Identity Status

Regarding social interpersonal identity, significant differences were observed in items as internet, decision making, and job between males and females of public school and English Institutes. Since the frequency results between these items were quite identical, the frequency result of internet was represented in Table 15. Males displayed diffusion at the age range 15 and 16 in public schools while their counterparts displayed diffusion and identity achievement in English institutes. At the age 17 and 18, males in public school moved toward identity achievement status meanwhile the frequency result of diffusion status remained remarkable. While females appeared to be more of foreclosures and moratoriums in public schools, they displayed more moratorium and identity achievement status in English institutes (see Table 15).

Table 15: The frequency Result of Gender and Age differences Considering Internet (face book, twitter,..) in SIIS

\begin{tabular}{|c|c|c|c|c|c|c|c|c|c|c|c|}
\hline \multirow{6}{*}{ Public School } & \multirow{2}{*}{ Age } & \multicolumn{4}{|c|}{ Frequency- Male/ Female } & & \multirow{2}{*}{ Age } & \multicolumn{4}{|c|}{ Frequency- Male/ Female } \\
\hline & & D & $F$ & $M$ & IA & & & D & $F$ & M & IA \\
\hline & 15 & $12 /$ & & & 4 & & 15 & 3 & & & 11 \\
\hline & 16 & & & & 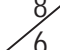 & $\begin{array}{l}\text { Engl|Sh } \\
\text { Institutes }\end{array}$ & 16 & & & & \\
\hline & 17 & 16) & 15 & $\frac{8}{12}$ & 20 & & 17 & $3 / 4$ & & 14 & $\frac{5}{12}$ \\
\hline & 18 & & & & & & 18 & & & & 18 \\
\hline
\end{tabular}

\section{Discussion and Conclusion}

This study determined to identify two goals: First to design and apply the identity status scale in public schools and English institutes and attain the reliability and validity of the scale. Second goal was to recognize age, gender and school differences in identity formation of young adolescents considering Marcia's four identity statuses, foreclosure, diffusion, moratorium, and identity achievement. Regarding the first goal of the study, the most pragmatic issues in social interpersonal religious, cultural, and political topics were taken into account to design a new scale and to apply it in two substantial settings of public schools and private English institutes. The results of Cronbach's Alpha, PCA, and Scree test diagram led to a reliable scale with four factor solution of the groupings in questionnaires items. The factors were specified as religious, social interpersonal, cultural, and political identities with $5,10,5$, and 5 items respectively. SEM 
was performed through LISREL program to realize the construct validity of the scale. The fitting indexes of $\mathrm{GFI}, \mathrm{NFI}, \mathrm{CFI}$, RMSEA as were discussed earlier resulted in correlated model and fitting indices. The study's four identities would be analyzed while distinguishing their relationship with Marcia's (1966) identity statuses in the second goal of the study. Considering the second goal of the study that was to recognize the age, gender, and school differences in identity formation of male and females, the four identities were analyzed respectively. Regarding religious identity, in contrast to the most studies which pinpointed the overall status of females being moratorium and identity achievers and males being mostly at the status of diffusion at the process of identity formation (Bradley \& Matsukis, 2000; Knafo et al., 2004; Lee et al., 1998; Yunus \& Kamal, 2010), the results of this study revealed that it is the value that determines the representation of a certain identity status. Females at the age of 15 and 16 in both settings indicated foreclosure status in religious sub factors mainly under the influence of their parents and ultimately under the influence of religion and at the age of 17 to 18 displayed more foreclosure and identity achievement statuses in public schools. It was explored that in spite of non- local cultural influence on youngsters, females still hold the collateral relationship with their parents in identifying and forming their commitment to their religious status and similar to the results of some studies, they scored higher than males on measures of religion (Goldstein, 2010; Lippman \& Keith, 2005). Males displayed diffusion status at the ages 15 and 16 and identity achievement at 17 and 18 revealing males' age maturation in attaining religious identity's sub factors.

In English institutes, the insignificant dominant effect of home religion on the content of the course books as well as the goals of the students leads to diffusion and foreclosure statuses for both males and females at the given age range resulting in detachment from home religion and attaching to non-local ones. Due to the secularity of the global culture and neglecting religious subjects, holistic consummation and individual entertainment have been promoted (Arnnet, 2002). This ignorance and the insignificant effect of religion on the identity formation of the individuals may cause diffusion, uncertainty, and distress. When comparing the frequency result of social interpersonal identity items, significant differences were revealed in internet, job, and decision making between the participants of the two settings. Some public school students suffer from English failure resulted in diffusion status in items as internet. Developing the more diffusion status may lead to the less social interpersonal, cultural, and political status. Insufficiency of proficient role model, the socio- economic disappointment (Sandhu \& Tung, 2006) as well as demotivation, ignorance, sense of loss, and deprivation (Tomlinson, 1999) are among the barriers that could firmly strengthen diffusion status. Some of English institutes participants' determined decision to designate a job related to EFL or to go abroad to continue their education makes them more vulnerable to foreign countries' culture, customs, and habits presented through the English institutes' course books and internet as well as the non- local powerful media. Though this continued enquiring and self exploration contributes to forming identity achievement and moratorium statuses, it may develop culture shedding eventually (Berry, 1997). That is to say, individuals who suffer from home detachment while attempting to achieve globalization, observe the extreme contradiction with the local identity, and so casual transformation of local identity to global one occurs.

Considering cultural identity, at the age range of 15 to 18, public school males are diffusions in items as first language and music. This frequent observance of males being at diffusion status could obviously present Erickson's (1963) confusion status leaving individuals with identity crisis. The sense of impermanence (Doku \& Asante, 2011) could be distinctly manifested in their inefficacious attitudes in presenting and deciding upon different life issues leading to a null identity. Females were identity achievers and foreclosures to secure their individuation and to adamantine their commitment and authority. The English institutes' participants significant differences with their counterparts in being identity achievers, moratoriums, and a few foreclosures would imply the concept of delocalization (Tomlinson, 1999) where their appetency toward a non- local culture localizes them straightly in the process of identity change. On the other hand, in both settings, few males and most females being at foreclosure and moratorium statuses implied their self exploration, self negotiation (Erickson, 1963), personal attachment, intimacy to their home culture, and at the same time their detachment to their home legacy. It seems that as adolescents' worldwide awareness in moratorium and identity achievement statuses grows, their 'displacement from home culture' also develops (Arnnet, 2002). These inconsistent polarization in achieving home attachment and detachment would be resulted from their perception of 'biculturalism' (Tadmor \& Tetlock, 2006) when they attempt to preserve their local identity while developing awareness and possible contentment of the global values, customs, experiences, and information. Regarding political identity, the fluctuated frequency result of public school male students between diffusion and moratorium statuses demonstrates the unresolved situation of being at confusion of preserving or fading their home attachment. Accordingly, the significant frequency results of some English institutes' participants in achieving political communication leads to gradual enlargement of nonlocal values, attitudes, and principles. The critical result was the negative convergence between cultural and political status implying the insignificant inclination of some of the participants to political status. Cultural heritage could be observed in ideas, norms, roles, individual feelings, and motives (Trommsdorff, 2012; Yasui \& Dishion, 2007). That is to say, one's objectives, ideology, values, and principles could be organized by cultural heritage. Conversely, in this study, a 
negative reciprocal correlation was explored between political and cultural statuses. This negative relationship would be the consequence of both the lack of delicate political and cultural clarification in both settings and solid influence of international media on home culture detachment. The media and the political organizations could divulge the broad scope of potential conflicts in adolescents (Coleman, 1992). This obvious contrast leads to unbalanced performance of individuals toward religious and political statuses ending with eccentric functioning of statuses, and ultimately leading to incongruent nationalism with positive attitudes toward non-local culture (Meja, 2010; Pishghadam, Hashemi, \& Bazri, 2013). Unlike Yunus and Kamal, (2010) who believed in the direct relationship between gender and identity formation classifying most females at moratorium and males at diffusion statuses, the mix representation of identity statuses among males and females in this study revealed the fact that individuals could not be characterized by some marked statuses. It is the momentous circumstance and intense manipulation of certain elements as music, clothes, and internet (face book, twitter) penetrating from non national entourages which entrap the real potential of individuals and inscribe the kind of behavior they represent. The casual detainment of this behavior would cause some psychological disappointment that fades the individuals' local identity at some life stages ending with cultural derichment (Pishghadam \& Saboori, 2014). Some few endeavors that could lessen the ascendancy of non- local identities as the by-product of non- local socialization and reinforce ethnocentrism- that part of individuals' self-concept and values acquired from their social group attachment (Tajfel, 1981) are to enhance the equal and interchangeable relationship between social interpersonal, religious, political, and cultural statuses, overall consciousness raising among vulnerable teenagers regarding international communication, and strengthening the sense of belonging to the native culture, values and home patriotic identity. Significance of this study would be observed in two different procurements in English language learning and teaching. The first importance of this study would be related to EFL teachers. Teachers would contribute to the students' movement toward identity achievement, where they can get free from identity crisis and become more of decision makers with high self esteem and low anxiety- two major values of adjustment. Secondly, policy makers could benefit from this scale in planning operational curriculums and functional materials in Iranian educational system while taking the students identity statuses into granted, and as Waterman (1982) asserts, successful model figures_ both teachers and policy makers_would contribute to the considerable meaningful commitments, decreasing the identity crisis, and exploring profitable identity content alternatives. The researchers acknowledge that this study confronted two major limitations. First, finding language learners with the exact age range of 15-18 in private English institutes was hard to accomplish and made us to apply the study among large number of participants. Second limitation was assigning two specific settings of public school and private English institutes. Therefore, to ensure the representation of the four identity statuses, other researchers would benefit from increasing the age range or changing the settings of the participants. Focusing on qualitative and quantitative analyses would be constructive in revealing the global interrelative correlation between social interpersonal, cultural, and political statuses. Finally, it would be advantageous to investigate the identity change of the participants in a longitudinal study considering their experiences, perceptions and late and matured values in their process of socialization, detachment or total adaptation.

\section{References}

Arnnet, J. J. (2002). The psychology of globalization. American Psychologist, 57(10), 774- 783.

Arseth A. K., Kroger, J., Martinussen, M., \& Marcia, J. E. (2009). Meta-analytic studies of identity status and the relational issues of attachment and intimacy. An International Journal of Theory and Research, 9(1), 1_32.

Bang, H. (2002). The relationship of wisdom and ego- Identity for Korean and American adolescents. Unpublished Dissertation, College of the Oklahoma, United States.

Berzonsky. M. D., Cieciuch, J., Duriez, B., \& Soenens, B. (2011). The how and what of identity formation: Associations between identity styles and value orientation. Personality and Individual Differences, 50, 295-299.

Coleman, J. (1992). The nature of adolescence. In J. Coleman (Ed.), Youth policies in the 1990's: The way forward, (pp. 8-27). London: Routledge, Taylor \& Francis Books Ltd.

Crocettia, E., Rubinib, M., \& Meeus, W. (2008). Capturing the dynamics of identity formation in various ethnic groups: Development and validation of a three- dimensional model. Journal of Adolescence, 31, 207-222.

Doku, P., \& Asante, K. ( 2011).Identity: Globalization, culture and psychological functioning. International Journal of Human Sciences, $8(2) \cdot 1-8$

Edwards, J. (2007). Language and identity. New York: Cambridge University Press.

Erikson, E.H. (1963). Childhood and society (2nd Eds) New York: W. W. Norton In K. D. Keith (Ed.), Cross cultural psychology contemporary themes and perspective. United Kingdom:Wiley- Blackwell.

Goffman, E. (1959). Presentation of self in everyday life. New York: Doubleday Anchor Books. Goldstein, S. N. (2010). The exploration of spirituality and identity status in adolescence. Currents: New Scholarship in the Human Services. 9(1), 1-22.

Hong,Y., Wan, C., No, S., \& Chiu, C. ( 2007). Multicultural identities In S. Kitayama \& D. Cohen (Eds), Handbook of cultural psychology, 
(pp. 323-345). New York: Guilford Press.

Knafo, A., Shalom H., \& Schwartz, S. (2004). Identity formation and parent-child value congruence in adolescence. British Journal of Developmental Psychology, 22, 439-458.

Kroger, J., \& Marcia, J. E. (2011). The, identity statuses: Origins, meanings and interpretations S. J. Schwartz, K. Luyckx, \& V. L. Vignoles, (Eds.), Handbook of identity theory and research: structures and processes (pp. 31-53). New York: Springer - Science.

Kumru, A., \& Thompson, R. A. (2003). Ego identity status and self- monitoring behavior in adolescents. Journal of Adolescent Research, 11(10), 1-16.

Lee, T. R., Kobayashi, N. J., \& Adams, G. R. (1988). Family influences on adolescent development in non-problematic L.D.S. families. AMCAP JOURNAL, 14 (1), 15-29.

Lee, W.S (2001). The effect of ethnic identity and language learning on Chinese adolescents' self-Esteem. Unpublished Master's Thesis, Graduate Division of Educational Research Calagary, Alberta.

Lippman, L. H., \& Keith, J. D. (2005). The demographics of spirituality among youth: International perspective. In E. C. Roehlkepartain, P. E , King, L, Wagner, \& P. L. Benson, (Eds.), The handbook of spiritual development in childhood and adolescence (pp. 109136). Thousand Oaks, CA: Sage

Marcia, J.E. (1966). Development and validation of ego-identity status. Journal of Personality and Social Psychology, 3 (5), $551-558$.

Marcia, J. E. (1980). Identity in adolescence. In J. Adelson (Ed.), Handbook of adolescent psychology (pp. 159-187). New York: Wiley.

Meeus, W., ledema, J., Helsen, M., \& Vollebergh, W. (1999). Patterns of adolescent identity development: Review of literature and longitudinal analysis. Developmental Review, 19, 419-461 In K. D. Keith (Ed.), Cross cultural psychology contemporary themes and perspective. (pp.75-109). United Kingdom: Wiley-Blackwell.

Meeus, W., Schoot, R.V., Keijsers, L., \& Branje, S. (2011). Identity statuses as developmental trajectories: A five-wave longitudinal study in early to middle and middle to late adolescents. J Youth Adolescence Retrieved 20 March 2013 from http/l. www. Springerlink.com.

Pishghadam, R., \& Motakef, R. (2011). Attributional patterns with respect to major and attendance in private language schools: A case of EFL context. Theory and Practice in Language Studies, 1(7), 888-894.

Pishghadam, R., \& Saboori, F. (2014). A Socio-cultural study of language teacher status. International Journal of Society, Culture \& Language, 2(1), 63-72.

Sandhu, D., \& Tung, S. (2006). Gender differences in adolescent identity formation. Pakistan Journal of Psychological Research, 21 (1), 29-49.

Sandhu, D., Singh, B., Tung, S., \& Kundra, N. (2012) Adolescent identity formation, psychological well-being, and parental attitudes. Pakistan Journal of Psychological Research, 27 (1), 89-105.

Schwartz, S. J., Cote, J. E., \& Arnett, J.J. (2005). Identity and agency in emerging adulthood: Two developmental routes in the individualization process. Youth \& Society, 37 (2), 201-229.

Smits, I, \& Soenensb, B., Luyckxa, K., 1, Durieza, B., Berzonsky, M., \& Goossens, L. (2008). Perceived parenting dimensions and identity styles: Exploring the socialization of adolescents processing of identity-relevant information. Journal of Adolescence, 31 , 151-164.

Tajfel, H. (1981). Human groups and social categories. New York, NY: Cambridge University Press.

Tatmor, C.T., \& Tetlock, P. E. (2006). Biculturalism: A model of the effects of second- culture exposure on acculturation and integrative. Journal of Cross Cultural Psychology, 37, 173- 190.

Tomlinson, J. B. (1999). Globalization and culture. Chicago: University of Chicago Press.

Trommsdorff, G. (2012). Cultural perspectives on values and religion in adolescent development. A conceptual overview and synthesis. In G.Trommsdorff (Ed.), Values, religion, and culture in adolescent development. (pp.3-45). New York: Cambridge University Press.

Waterman, A.S., Geary, P.S. \& Waterman, C.K. (1974). Longitudinal study of changes in ego identity status from the freshman to the senior year at college. Developmental Psychology, 10, 387-392.

Waterman, A. S. (1982). Identity development from adolescence to adulthood: An extension of theory and a review of Research. Developmental Psychology, 18(3), 341-358.

Waterman, A. S. (1999). Identity, the identity statuses, and identity status development: A contemporary statement. Developmental Review, 19, 591-621.

Yasui, M., \& Dishion, T. J. (2007). The ethnic context of child and adolescent problem behavior: Implications for child and family interventions. Clinical Child and Family Psychology, 10 (2),137-179.

Yunus, F. W., \& Kamal, A. (2010). Gender differences on the identity status of the Malaysian preparatory students. Canadian Social Science, 6 (2), 145-151. 